International Journal of Health Sciences
Available online at www.sciencescholar.us
Vol. 5 No. 3, December 2021, pages: 639-648
e-ISSN: 2550-696X, p-ISSN: 2550-6978
https://doi.org/10.53730/ijhs.v5n3.2790

\title{
Personal Factors of Biological Aging in Working and Non- Working Respondents in Late Maturity Period
}

\author{
CrossMark
}

Azalia Maratovna Zinatullina a , Vadim Pavlovich Melnik ${ }^{b}$, Albina Aleksandrovna Zimina ${ }^{c}$

Manuscript submitted: 24 July 2021, Manuscript revised: 02 October 2021, Accepted for publication: 26 November 2021

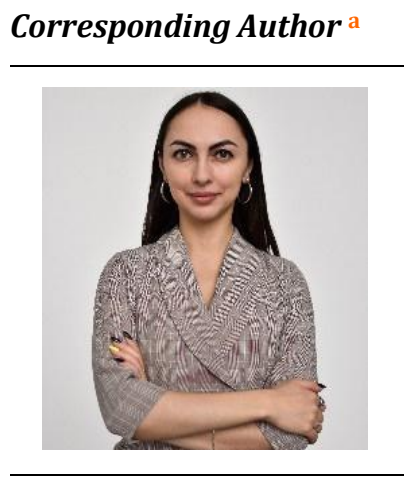

Keywords

health indicators;

health questionnaire;

higher education;

mature age;

psychological age;

work activity;

\begin{abstract}
The aim was to study the influence of personal factors on the index of individual biological aging in men and women of mature age who continue to work and those who no longer work. The participants were 347 people, including 212 women aged 56-65 years and 111 men aged 61-69 years. Measurement of biological age, relative biological aging index, assessment of subjective psychological age, expected retirement age, life path questionnaire. Biological age was estimated using a formula that included indicators of metabolism, the work of the cardiovascular, respiratory, and balance organ systems; a psychological health questionnaire was also used. The lowest index of relative biological aging was found in people who continued to work parttime. There is a relationship between the index of relative biological aging and one's characteristics. For men, the index was lowered by the following factors: changing the place of residence, continuing to work after retirement, a high indicator of the expected retirement age, and increased by living in a large city. For women, the index was lowered by the following factors: changing the place of residence, continuing to work after retirement, a high indicator of the expected retirement age, higher education, creative hobbies, studying after retirement.
\end{abstract}

International Journal of Health Sciences (C) 2021. This is an open access article under the CC BY-NC-ND license (https://creativecommons.org/licenses/by-nc-nd/4.0/).

\section{Contents}

Abstract

1 Introduction

2 Materials and Methods.

3 Results and Discussions

\footnotetext{
a Moscow State University of Psychology and Education, Moscow, Russia

${ }^{\text {b }}$ Moscow State University of Psychology and Education, Moscow, Russia

c Moscow State University of Psychology and Education, Moscow, Russia
} 


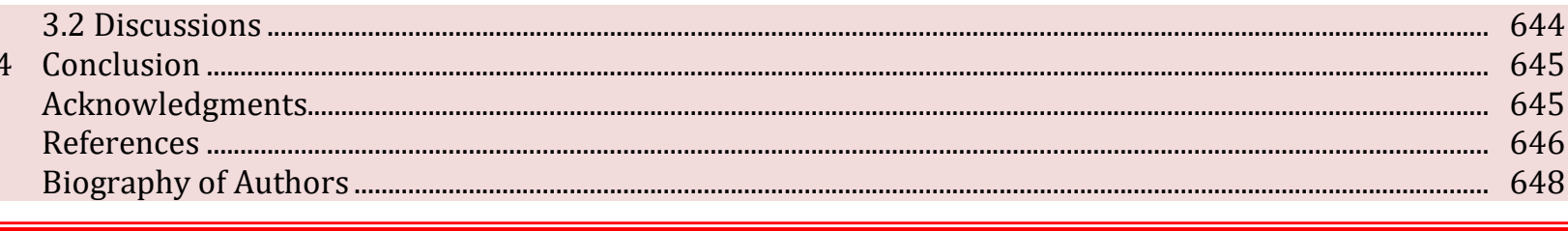

\section{Introduction}

The identification of epigenetic and behavioral factors affecting the acceleration and deceleration of individual aging is currently becoming the leading topic of many multidisciplinary studies (Derisbourget al., 2021). The goal of psychology is to identify the personal factors that are amenable to conscious regulation by the individual. Among the most important factors potentially affecting the acceleration and deceleration of individual aging of adults, one can name the continuation of work in mature age and features of the individual's life path (Berezina, 2020), life satisfaction, and optimism (Berezina \& Buzanov, 2021), stress resistance and health indicators (Rybtsova et al., 2020). The most important thing is that these factors are amenable to conscious regulation. A person can change their life path, for example, by continuing to work after the retirement age or by retiring from work (Lengen et al., 2019; Carpenter et al., 2004). A person can start studying or combine studies with work. Besides that, a person can have various hobbies and interests, attend various workshops to develop positive thinking or to increase stress tolerance.

Termination of employment during late maturity is one of the most significant factors of individual aging. Many researchers conclude that the risk of premature death after retirement increases regardless of the country of the study, be it Greece (Bamia et al., 2008), Germany (Brockmann et al., 2009); Sweden (Karlsson et al., 2007); USA (Tsai et al., 2005), or Russia (Rybtsov \& Berezina, 2020). Conversely, continuing to work at a late mature age is considered a favorable factor for human health and life expectancy (Pit et al., 2013; Elnar et al., 2016). According to the results of a study by Kuhn et al. (2010), in Austria, men who retire a year ahead of schedule have a higher likelihood of dying compared to those continuing to work (by 2.4 percentage points or $13 \%$ ). Many studies are devoted to the deterioration of health after retirement, and most authors show that the deterioration of health is observed in both men and women (Kurtieva et al., 2021). In the USA, it has also been shown that the dismissal of employees upon reaching retirement age leads to an increase in the risk of myocardial infarction by 2.48 percentage points and the risk of stroke by 2.43 percentage points (Gallo et al., 2006). These data were confirmed by another study, also conducted based on the Health and Retirement Survey (HRS). Analysis of statistical data showed that over 6 years after retirement, difficulties in movement increased by $5-16 \%$, and the overall disease incidence by $5-6 \%$. To the greatest extent, the negative effect is manifested among people who did not experience health problems before retirement: among them, difficulties in movement increase by $17-22 \%$, and the overall disease incidence by $6 \%$. At the same time, with part-time employment after reaching retirement age, the disease incidence increases by only $4.2 \%$, and difficulties in performing daily activities by $10 \%$ (Dave et al., 2008; Aryani \& Lesmana, 2019).

In addition to retirement stress, many other psychological and behavioral factors affect a person's life expectancy and health; the person's behavior, lifestyle, daily routine, and worldview affect their biological age, even determined at the chromosomal level (Boutari \& Mantzoros, 2017; Stellos \& Spyridopoulos, 2019). Some of the mental and behavioral factors have a beneficial effect, increasing a person's health and well-being, for example, the inclusion of endurance training in the normal daily routine of healthy people affects telomerase activity and telomere length (Werner et al., 2019; Widana et al., 2021). Lifestyle changes, the inclusion of extreme training into one's regime, increased the activity of telomerase and other enzymes that were important for cellular aging, regenerative ability, and, consequently, this led to a slowdown in aging (Sallis et al., 1998; Washburn et al., 1999).

The health of people of mature age is influenced by the following features of their life path: the level of education (Cutler \& Lleras-Muney, 2010), a variety of interests, and hobbies that a person had during their life. The influence of interests and hobbies on life expectancy has been noted by many researchers, for example, it has been noted that playing sports, having sports hobbies-related and interests contribute to improving health, life expectancy, and reducing social frustration (Morozova et al., 2015; Santi et al., 2021). 
The purpose of this study is a comparative analysis of personal factors affecting the dynamics of the biopsychological age of respondents who were retired, but some of them continued working and others did not.

\section{Materials and Methods}

\section{Diagnostic methods}

- We followed the methodology "Determination of biological age according to V.P. Voitenko" [Voitenko 82]. The biological age (BA) indicator was calculated as it required to calculate the index of relative biological aging. Additionally, we determined the indicator of proper biological age (PBA). PBA is a statistical norm of biological age, and this indicator is also necessary for calculating the index of relative biological aging. The detailed methodology has been published in (Berezina, 2020b).

- The index of relative biological aging equals BA - PBA. Negative values indicate that the person's aging is slower than the average, and positive values indicate individual aging relative to statistical norms.

- Self-assessment of subjective psychological age was performed according to K.A. Abulkhanova and T.N. Berezina. The participants were asked to estimate their age on a 100 -point scale, where 0 points were the age of a newborn baby, and 100 points were the age of a person who had already achieved everything and would not be able to achieve more. The psychological age (PA) indicator was measured; it was considered as the individual's level of self-realization, achievements, and potential. The detailed methodology has been published in (Berezina et al., 2020).

- The index of relative psychological aging equals PA - CA (calendar age). Negative values indicate that the person feels younger than their real age and thinks that they still have a lot to achieve. Positive values indicate that the person feels more mature, wiser, and thinks that they have achieved greater results than would be assumed by CA.

- The index of personal (psychobiological) maturity was calculated as the ratio of subjective PA to BA.

- The expected retirement age scale. The expected retirement age was calculated as the arithmetic mean of the participant's answers to the following questions: "At what age do you plan to retire?", "At what age do people of your gender retire in your country?", "Ideally at what age would you like to retire?", "What is the minimum retirement age for yourself that you would like?", "What is the maximum (latest) retirement age for yourself that you would think of?" The detailed methodology has been published in (Berezina et al., 2020).

- The life path questionnaire. Original development. The participants were asked to name their profession, education, level of career achievements, religiosity, place of residence, family and children, bad habits (smoking, overeating, alcoholism), etc.

- We used Dembo-Rubinstein's method of self-assessment of one's personality traits in our modification. The participants were asked to evaluate the following personality traits: aggressiveness, activity, sociability, caring (the presence of someone to care for), optimism. After that, the self-assessment of indicators was reduced to 3 levels: low, medium, and high.

Statistical methods:

- ANOVA analysis of variance (one-factor analysis to assess the influence of the factor "continuation of work after retirement" on the indicators of biopsychological age; two-factor analysis to assess the interaction of the factor "continuation of work in retirement" with life path factors in their influence on the index of relative biological aging). To compare the groups with each other, we used Fisher's LSD, which is part of the analysis of variance.

- Correlation analysis. We calculated the Pearson correlation coefficient to assess the relationship of personality characteristics and one's life path with the index of relative biological aging of an individual.

Zinatullina, A. M., Melnik, V. P., \& Zimina, A. A. (2021). Personal factors of biological aging in working and nonworking respondents in late maturity period. International Journal of Health Sciences, 5(3), 639-648. https://doi.org/10.53730/ijhs.v5n3.2790 
Participants: 347 people of mature age, including 212 women aged 56-65 years and 111 men aged 61-69 years. Among the women: 131 were unemployed, 2 people worked part-time, 79 people worked full-time (continuing to work at the same place as before reaching the retirement age). Among the men: 63 were unemployed, 14 people worked part-time, 34 people worked full-time (continuing to work at the same place as before reaching the retirement age). All the participants resided in Moscow and received medical care in one of the city clinics.

\section{Results and Discussions}

\subsection{Results}

The most important indicator characterizing the biological age of an organism and its state of health is the index of relative biological aging. We looked at the interrelationships of this index with the characteristics of personality and its life path among retired men and women (Table 1).

Table 1

Correlation coefficients of the index of relative biological aging with indicators of the life path and personality

\begin{tabular}{lll}
\hline & Men & Women \\
\hline Living in a large city & $0.33^{* * *}$ & $0.44^{* * *}$ \\
Changing the place of residence & $-0.29^{* *}$ & $-0.34^{* * *}$ \\
Number of years of work after the retirement age & $-0.24^{*}$ & \\
Expected retirement age & $-0.56^{*}$ & $-0.43^{* *}$ \\
Continuing to work after retirement & -0.18 & $-0.20^{* *}$ \\
education & & $-0.20^{* *}$ \\
family & & $0.20^{* *}$ \\
Creative hobbies & & $-0.27^{* * *}$ \\
aggressiveness & & $0.30^{* * *}$ \\
Life satisfaction and optimism & $-0.17^{*}$ \\
Currently studying & & $-0.40^{* * *}$ \\
\hline
\end{tabular}

$* \mathrm{p}<0.05$

$* * \mathrm{p}<0.01$

$* * * \mathrm{p}<0.001$

As can be seen from the table, in men, the relative aging index is lowered by the following life path features: the number of times they changed their place of residence, the number of years of work after reaching the retirement age, the continuation of work after the retirement age at the time of the survey, a high indicator of the expected retirement age, and the index is increased only by living in a large city (Mustika et al., 2021).

For women, the index is lowered by the following factors: changing the place of residence, continuing to work after reaching the retirement age, a high indicator of the expected retirement age, having a higher education, creative hobbies, studying after retirement, life satisfaction, and it was increased by such factors as living in a large city, aggressiveness, or having a family (Zhang et al., 2020; Serin et al., 2010). Next, we looked at how the factor of continuing to work after the retirement age affected the indicators of the biopsychological age of men (Table 2) and women (Table 3). 
Table 2

Indices of biopsychological aging in working and non-working pensioners (men and women)

\begin{tabular}{|c|c|c|c|c|c|}
\hline \multicolumn{6}{|l|}{ Men } \\
\hline & 1 & 2 & 3 & $\mathrm{~F}$ & $\mathrm{p}$ \\
\hline & $\begin{array}{l}\text { Non- } \\
\text { working }\end{array}$ & $\begin{array}{l}\text { Working part- } \\
\text { time }\end{array}$ & $\begin{array}{l}\text { Working full- } \\
\text { time }\end{array}$ & & \\
\hline Index of relative & 4.73326 & -7.48650 & 2.23965 & $F(2,108)=$ & $\mathrm{p}=0.00000$ \\
\hline biological aging & & & & 14.056 & \\
\hline Index of relative & -2.5000 & 13.9091 & -11.3333 & $\mathrm{~F}(2,50)=$ & $p=0.00017$ \\
\hline $\begin{array}{l}\text { psychological aging } \\
\text { Personal maturity index }\end{array}$ & 1.070784 & 1.573023 & 0.909899 & $\begin{array}{l}10.345 \\
: F(2,50)= \\
14.349\end{array}$ & $p=0.00001$ \\
\hline \multicolumn{6}{|l|}{ Women } \\
\hline $\begin{array}{l}\text { Index of relative } \\
\text { biological aging }\end{array}$ & 1.9809 & -14.4150 & -1.6263 & $\begin{array}{l}F(2209)= \\
7.2680\end{array}$ & $p=0.00089$ \\
\hline $\begin{array}{l}\text { Index of relative } \\
\text { psychological aging }\end{array}$ & -3.7059 & -21.0000 & 2.3500 & $\begin{array}{l}: F(2,52)= \\
1.0500\end{array}$ & $\mathrm{p}=0.35725$ \\
\hline Personal maturity index & 1.123202 & 0.888889 & 1.664802 & $\begin{array}{l}F(2,52)= \\
4.3299\end{array}$ & $\mathrm{p}=0.01822$ \\
\hline
\end{tabular}

As can be seen from the table, the factor of continuing to work after reaching the retirement age has a significant impact on all temporal indicators. For the index of relative biological aging, this is not a linear, but a U-shaped dependence. For men and women, the average group, i. e. the pensioners who continue to work on a part-time basis after reaching the retirement age, show the best indicators. The second place is occupied by pensioners working full-time, and the non-working pensioners are at the last place. Pensioners working parttime have a negative index of relative biological aging, i.e. they are biologically younger than their peers, and pensioners working full-time are biologically a little older.

For the index of relative psychological aging, the relationship is also U-shaped, but it is reversed and is present only in men. Psychologically, men who continue to work part-time consider themselves older. The pensioners working full-time demonstrate the opposite trend in terms of psychological time; they consider themselves psychologically very young, younger than all other groups, less self-realized, and they think that they still have a lot ahead of them. Pensioners who have stopped working show the most adequate values: their PA is close to the CA, and the personal maturity index is 1.

Next, we separately highlighted the characteristics of the life path and personality traits that are favorable for working and for non-working pensioners. The analysis was made only for men (Table 3); we did not conduct a similar analysis for women, due to the very small volume of the group of part-time employees, because it would be impossible to assess the reliability of its results, and the available data were close to the results of the correlation analysis presented above.

Table 3

The index of relative aging in working and non-working retired men with different characteristics of the life path (only reliable data)

\begin{tabular}{lllllll}
\hline Indicator & Levels & $\begin{array}{l}1 \\
\text { Non-working }\end{array}$ & $\begin{array}{l}2 \\
\text { Working part- } \\
\text { time }\end{array}$ & $\begin{array}{l}3 \\
\text { Working } \\
\text { time }\end{array}$ & full- & \\
\hline Religiosity & 1 & 4.1517 & -10.9903 & 5.4823 & $\mathrm{~F}(3,110)$ & $\mathrm{p}=0.0124$ \\
& 2 & 6.2729 & -4.8586 & -1.8311 & $=3.7935$ & 0 \\
Career & 3 & -3.1710 & & -2.3810 & & \\
\hline
\end{tabular}

Zinatullina, A. M., Melnik, V. P., \& Zimina, A. A. (2021). Personal factors of biological aging in working and nonworking respondents in late maturity period. International Journal of Health Sciences, 5(3), 639-648. 


\begin{tabular}{|c|c|c|c|c|c|c|}
\hline & 2 & 4.1384 & -5.7602 & 0.7904 & $=2.5212$ & 5 \\
\hline & 3 & 5.3087 & -0.2430 & 6.6443 & & \\
\hline & 4 & 3.8816 & -6.6880 & -10.0425 & & \\
\hline \multirow{3}{*}{$\begin{array}{l}\text { Intellectual } \\
\text { hobbies }\end{array}$} & 1 & 5.6242 & -0.9718 & -0.2008 & $F(5,106)$ & $p=0.0129$ \\
\hline & 2 & 5.0233 & -12.2267 & 2.9792 & & \\
\hline & 3 & 2.9125 & -12.8100 & 6.2330 & & \\
\hline \multirow[t]{3}{*}{ Sociability } & 1 & 20.1665 & -0.4970 & - & $\mathrm{F}(3,110)$ & $\mathrm{p}=0.0334$ \\
\hline & 2 & 1.0096 & -5.1548 & 2.9626 & $=3.0060$ & 6 \\
\hline & 3 & 5.6417 & -12.1480 & 1.2069 & & \\
\hline \multirow[t]{3}{*}{$\begin{array}{l}\text { Having someone } \\
\text { to care for }\end{array}$} & 1 & -0.6353 & -16.9460 & 4.7860 & $\begin{array}{l}: F(4,109) \\
=3.0600\end{array}$ & $\begin{array}{l}p=0.0196 \\
8\end{array}$ \\
\hline & 2 & 5.4885 & -2.4760 & -0.6751 & & \\
\hline & 3 & 5.1038 & -9.3438 & 5.7629 & & \\
\hline
\end{tabular}

Level 1 means that the value is low, this indicator has minimal values or is equal to 0 .

2 is the average level. This indicator is partially expressed or was expressed sometimes throughout the person's life.

3 is a high level. This indicator is present throughout the life path.

4 is a very high level.

- means that the indicator was not determined due to the absence of respondents.

As can be seen from the table, personal factors have a different effect on the index of relative biological aging, depending on whether the person continues to work after reaching retirement age. Personal factors that affect individual aging in different ways include one's religiosity, career, intellectual hobbies, sociability, and whether or not the person has someone to care for.

\subsection{Discussion}

Let us take a closer look at the personal factors that influence the acceleration or deceleration of biological aging in working and non-working male pensioners. Firstly, religiosity. For non-working male pensioners, going to church regularly is favorable, for those working with permanent employment, any religiosity is favorable. Part-time pensioners have better results with atheism or partial religiosity. Secondly, the career. The continuation of full-time work after reaching the retirement age is favorable only at a very high level of the career ladder and is unfavorable at the low and medium levels. Continuing to work part-time (and changing jobs) is favorable at any career level, and most favorable at a low level. The initial career level for non-working pensioners probably does not have a significant impact on the relative aging index. Thirdly, intellectual hobbies. This is a very favorable factor for part-time pensioners. For full-time pensioners, it becomes unfavorable, and for non-working people, it does not make a big difference. Fourth, sociability is also a very favorable factor for part-time pensioners; for full-time pensioners, the factor most likely does not influence their life, since their level of sociability is already high (apparently in connection with work). For non-working pensioners, the factor is rather favorable. Fifth, the presence of someone to care for. For nonworking male pensioners, the presence of someone to care for is an unfavorable factor; for full-time workers, it is favorable to have an object of care that requires little care. For part-time workers, it is most likely better not to have anyone to care for.

The situation is generally similar for women, but in their case, female pensioners who continued to work immediately after reaching the retirement age do not differ in biopsychological indicators from those who left work, although in general, the trend persists that women who continue to work turn out to be biologically younger. For women, the continuation of work itself is already a positive factor that supports health, but at the same time, the continuation of part-time work is positive. For women, more factors are positive in terms of maintaining health: in addition to continuing to work after retirement, and various types of activities, the following factors are positive: having an education, receiving additional education after retirement, optimism. The negative factors are aggressiveness and concentration on the family. 
In our study, we found a group of respondents whose behavior after retirement could be considered ideal in terms of slowing down the pace of relative biological aging. These are men who have continued to work after retirement, but only with part-time employment (Hayward et al., 1994). This group included men who, after retirement, had changed their profession, or transferred to another job, or simply stayed at the same place, but on a part-time basis. This group includes both people who have not made any career advances and those who have achieved professional success. We believe that this group was made up of men who took advantage of retirement to change their lives for the better. On the one hand, maintaining part-time employment gave these respondents positive socialization, a sense of inherent importance, financial support, and on the other hand, since they were employed part-time, they had more time for rest and some other activities and hobbies. Engaging in one's interests is favorable for this group. The most favorable factor for men employed part-time is the development of intellectual hobbies, productive personal communication, and the expansion of their social circle.

A similar strategy is also suitable for women (partial professional employment with the development of their interests and hobbies), but only 1 percent of female pensioners choose it. For women, this is also a very favorable strategy that helps slow down the rate of biological aging. It can be assumed that for women, in this case, the development of creative hobbies, obtaining additional education, and perhaps a change of activity would be a more suitable path. This coincides with the literature data that showed a positive effect of getting a master's degree on the health of women of retirement age.

\section{Conclusion}

- The lowest index of relative biological aging was found in mature respondents who continued to work part-time. Continuing to work full-time was less favorable. Stopping work completely was even less favorable. In men, the lowest indicators of the relative biological aging index were found in the men who continued working part-time. Biologically, they were on average 20 years younger than their peers, but psychologically they considered themselves older than their peers, thinking they had achieved great results but had fewer opportunities for further growth. In mature women, the lowest rates of biological aging were also observed in those who continued to work part-time; they were on average 15 years younger than their peers. In second place were the women who continued to work full-time, and in third place were the women who had left work.

- There is a relationship between the index of relative biological aging and personal characteristics. In men, the relative aging index is lowered by the number of relocations, continued work after retirement, a high indicator of the expected retirement age, and increased only by living in a large city. In women, the relative aging index is lowered by changing the place of residence, continuing to work after retirement, a high indicator of the expected retirement age, higher education, creative hobbies, studying after retirement, life satisfaction, and increased by living in a large city, aggressiveness, or having a family.

- Personal factors contributing to the slowing down of biological aging differ in men who continue their work and those who have stopped it. For those who have stopped working, a high level of religiosity, church attendance, the presence of intellectual hobbies, average sociability, the presence of someone to care for is favorable. For those who continue to work full-time, high and medium-level religiosity, a medium career level, caring for someone who requires little care are also favorable. For part-time workers, religiosity does not matter, the career level may be insignificant, and it is favorable to have intellectual hobbies and a large social circle.

\section{Acknowledgments}

The article has been prepared with the financial support of the Russian Science Foundation, Project No. 19-1800058 .

Zinatullina, A. M., Melnik, V. P., \& Zimina, A. A. (2021). Personal factors of biological aging in working and nonworking respondents in late maturity period. International Journal of Health Sciences, 5(3), 639-648. 


\section{References}

Aryani, L. N. A., \& Lesmana, C. B. J. (2019). Neuropsychiatric factor and polymorphism gene in internet addiction. International Journal of Health \& Medical Sciences, 2(1), 39-44.

Bamia, C., Trichopoulou, A., \& Trichopoulos, D. (2008). Age at retirement and mortality in a general population sample: the Greek EPIC study. American Journal of Epidemiology, 167(5), 561-569.

Berezina, T. (2020). Differences in individual life path choices affecting life expectancy and health in Russia. In E3S Web of Conferences (Vol. 210, p. 17032). EDP Sciences.

Berezina, T. (2020). Distribution of biomarkers of aging in people with different personality types (in Russia). In E3S Web of Conferences (Vol. 210, p. 17028). EDP Sciences.

Berezina, T. N., Rybtsova, N. N., \& Rybtsov, S. A. (2020). Comparative dynamics of individual ageing among the investigative type of professionals living in Russia and Russian migrants to the EU countries. European Journal of Investigation in Health, Psychology and Education, 10(3), 749-762.

Berezina, T. N., Rybtsova, N. N., Rybtsov, S. A., \& Fatyanov, G. V. (2020). Individual-personal factors of retirement stress among representatives of the intellectual type living in Russia and immigrating to the EU countries. Journal of Modern Foreign Psychology, 9(1), 8-21 (in Russ.).

Berezina, T., \& Buzanov, K. (2021). Personal characteristics affecting the biological age of the individual. In E3S Web of Conferences (Vol. 284, p. 09008). EDP Sciences.

Boutari, C., \& Mantzoros, C. S. (2017). Decreasing lean body mass with age: challenges and opportunities for novel therapies. Endocrinology and Metabolism, 32(4), 422-425.

Brockmann, H., Müller, R., \& Helmert, U. (2009). Time to retire-Time to die? A prospective cohort study of the effects of early retirement on long-term survival. Social science \& medicine, 69(2), 160-164. https://doi.org/10.1016/j.socscimed.2009.04.009

Carpenter, J. P., Anderson, W. N., Brewster, D. C., Kwolek, C., Makaroun, M., Martin, J., ... \& Lifepath Investigators. (2004). Multicenter pivotal trial results of the Lifepath System for endovascular aortic aneurysm repair. Journal of vascular surgery, 39(1), 34-42. https://doi.org/10.1016/j.jvs.2003.10.036

Cutler, D. M., \& Lleras-Muney, A. (2010). Understanding differences in health behaviors by education. Journal of health economics, 29(1), 1-28. https://doi.org/10.1016/j.jhealeco.2009.10.003

Dave, D., Rashad, I., \& Spasojevic, J. (2008). The effects of retirement on physical and mental health outcomes. Southern Economic Journal, 75(2), 497-523.

Derisbourg, M. J., Hartman, M. D., \& Denzel, M. S. (2021). Modulating the integrated stress response to slow aging and ameliorate age-related pathology. Nature Aging, 1(9), 760-768.

Elnar, A. A., Allouche, A., Desor, F., Yen, F. T., Soulimani, R., \& Oster, T. (2016). Lactational exp osure of mice to low levels of non-dioxin-like polychlorinated biphenyls increases susceptibility to neuronal stress at a mature age. Neurotoxicology, 53, 314-320. https://doi.org/10.1016/j.neuro.2015.10.003

Gallo, W. T., Teng, H. M., Falba, T. A., Kasl, S. V., Krumholz, H. M., \& Bradley, E. H. (2006). The impact of late career job loss on myocardial infarction and stroke: a 10 year follow up using the health and retirement survey. Occupational and environmental medicine, 63(10), 683-687.

Hayward, M. D., Hardy, M. A., \& Liu, M. C. (1994). Work after retirement: The experiences of older men in the United States. Social Science Research, 23(1), 82-107. https://doi.org/10.1006/ssre.1994.1004

Karlsson, N. E., Carstensen, J. M., Gjesdal, S., \& Alexanderson, K. A. (2007). Mortality in relation to disability pension: findings from a 12-year prospective population-based cohort study in Sweden. Scandinavian journal of public health, 35(4), 341-347.

Kuhn, A., Wuellrich, J. P., \& Zweimüller, J. (2010). Fatal attraction? Access to early retirement and mortality.

Kurtieva, S., Nazarova, J., \& Mullajonov, H. (2021). Features of endocrine and immune status in adolescents with vegetative dystonia syndrome. International Journal of Health Sciences, 5(2), 118-127. https://doi.org/10.29332/ijhs.v5n2.1332

Lengen, C., Timm, C., \& Kistemann, T. (2019). Place identity, autobiographical memory and life path trajectories: The development of a place-time-identity model. Social Science \& Medicine, 227, 21-37. https://doi.org/10.1016/j.socscimed.2018.09.039

Morozova, E. V., Shmeleva, S. V., Sorokoumova, E. A., Nikishina, V. B., \& Abdalina, L. V. (2015). Acceptance of disability: determinants of overcoming social frustration. Global journal of health science, 7(3), 317. 
Mustika, I. W., Kuswardhani, R. T., Suastika, K., Adiatmika, I. P. G., \& Iswara, N. P. A. A. P. (2021). Implementation of bali elderly care model to increase melatonin levels in elderly community. International Journal of Health Sciences, 5(2), 151-159. https://doi.org/10.29332/ijhs.v5n2.1362

Pit, S. W., Shrestha, R., Schofield, D., \& Passey, M. (2013). Partial and complete retirement due to ill-health among mature age Australians. Public Health, 127(6), 561-571. https://doi.org/10.1016/j.puhe.2012.12.022

Rybtsov, S., \& Berezina, T. (2020). 3128-The Retirement Stress Increases Biological Age: Searching StressInduced Inflammatory And Immunosenescence Factors Of Biological Aging Acceleration. Experimental Hematology, 88, S78. https://doi.org/10.1016/j.exphem.2020.09.137

Rybtsova, N., Berezina, T., Kagansky, A., \& Rybtsov, S. (2020). Can blood-circulating factors unveil and delay your biological aging?. Biomedicines, 8(12), 615.

Sallis, J., Bauman, A., \& Pratt, M. (1998). Environmental and policy interventions to promote physical activity. American journal of preventive medicine,15(4), 379-397. https://doi.org/10.1016/S07493797(98)00076-2

Santi, L. K. S., Sudewi, A. A. R., Duarsa, D. P., \& Lesmana, C. B. J. (2021). The effect of pregnancy massage on level of depression, anxiety and stress in pregnant women. International Journal of Health \& Medical Sciences, 4(2), 220-225.

Serin, N. B., Serin, O., \& Özbaş, L. F. (2010). Predicting university students' life satisfaction by their anxiety and $\begin{array}{llll}\text { depression level. Procedia-Social and Behavioral } & \text { Sciences, 9, }\end{array}$ https://doi.org/10.1016/j.sbspro.2010.12.200

Stellos, K., \& Spyridopoulos, I. (2019). Exercise, telomerase activity, and cardiovascular disease prevention. European heart journal.

Tsai, S. P., Wendt, J. K., Donnelly, R. P., De Jong, G., \& Ahmed, F. S. (2005). Age at retirement and long term survival of an industrial population: prospective cohort study. Bmj, 331(7523), 995.

Washburn, R. A., McAuley, E., Katula, J., Mihalko, S. L., \& Boileau, R. A. (1999). The physical activity scale for the elderly (PASE): evidence for validity. Journal of clinical epidemiology,52(7), 643-651. https://doi.org/10.1016/S0895-4356(99)00049-9

Werner, C. M., Hecksteden, A., Morsch, A., Zundler, J., Wegmann, M., Kratzsch, J., ... \& Laufs, U. (2019). Differential effects of endurance, interval, and resistance training on telomerase activity and telomere length in a randomized, controlled study. European heart journal, 40(1), 34-46.

Widana, I.K., Sumetri, N.W., Sutapa, I.K., Suryasa, W. (2021). Anthropometric measures for better cardiovascular and musculoskeletal health. Computer Applications in Engineering Education, 29(3), 550561. https://doi.org/10.1002/cae.22202

Zhang, S. X., Wang, Y., Rauch, A., \& Wei, F. (2020). Unprecedented disruption of lives and work: Health, distress and life satisfaction of working adults in China one month into the COVID-19 outbreak. Psychiatry research, 288, 112958. https://doi.org/10.1016/j.psychres.2020.112958

Zinatullina, A. M., Melnik, V. P., \& Zimina, A. A. (2021). Personal factors of biological aging in working and nonworking respondents in late maturity period. International Journal of Health Sciences, 5(3), 639-648. 


\section{Biography of Authors}

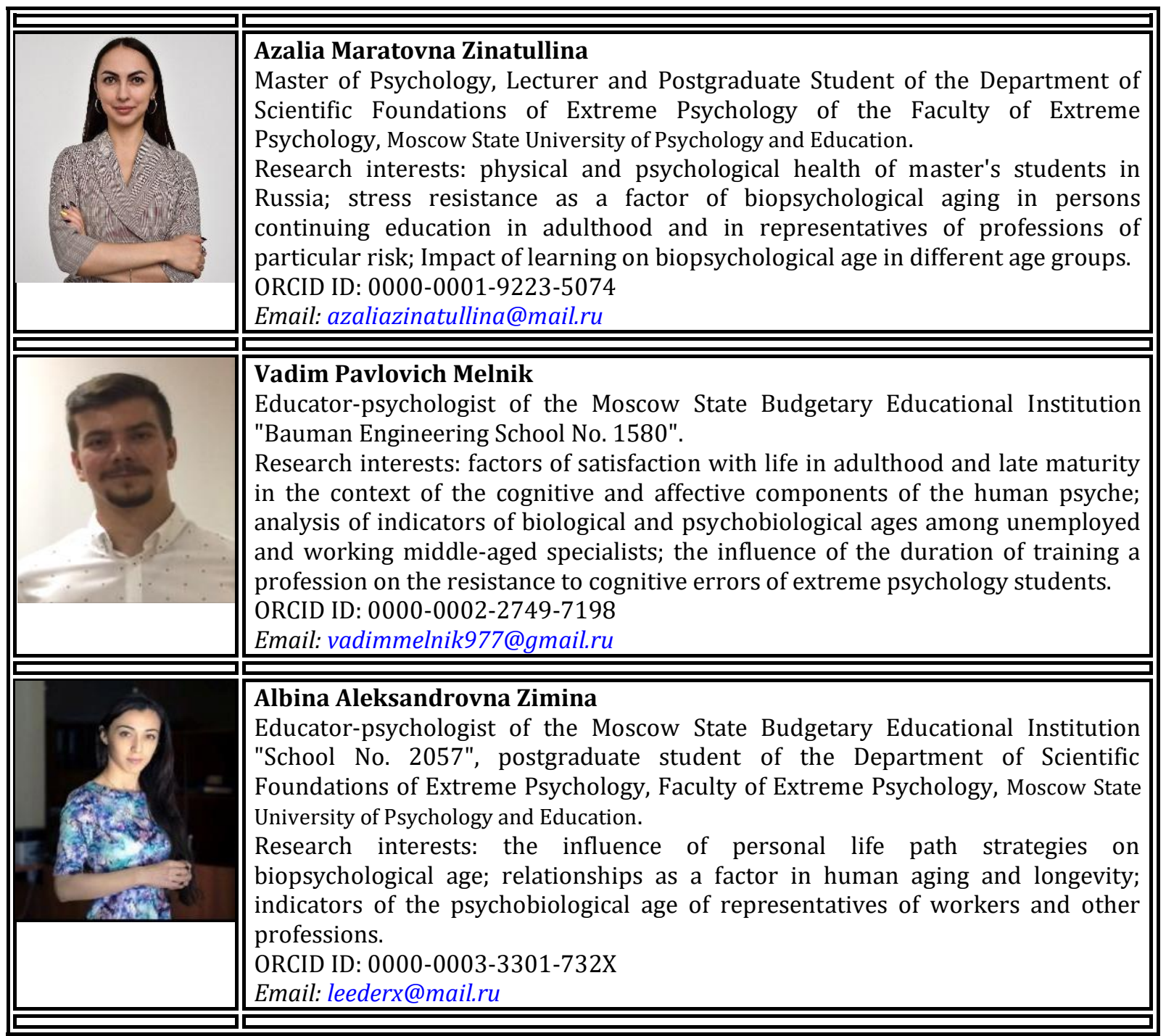

